\title{
Simulation of Adsorption Kinetics of Malachite Green onto Activated Carbon
}

\author{
Z. Benmaamar, ${ }^{a}{ }^{*}$ H. Boutoumi, ${ }^{b}$ H. Hamitouche, ${ }^{a}$ H. Benmaamar, ${ }^{a}$ \\ A. Benmaamar, ${ }^{a}$ A. Benmaamar, ${ }^{a}$ and A. Aggoun $^{b}$ \\ ${ }^{a}$ Laboratoire d'Application Energétique de l'Hydrogène, University of Blidal, \\ Soumaa, 9000 Blida, Algeria \\ ${ }^{b}$ Laboratoire de Génie Chimique, University of Blidal, Soumaa,9000 Blida, Algeria
}

Received August 10, 2016; accepted June 13, 2017

\begin{abstract}
In this work, activated carbon was produced from residue of fruit of Sapindus and used for the application of adsorption removal of malachite green dye from simulated aqueous solution. Adsorption kinetics of malachite green onto actived carbon was studied in a batch system. The effects of $\mathrm{pH}$ and contact time were examined. The malachite green maximum adsorption occurred at $\mathrm{pH} 6(4.5 \mathrm{mg} / \mathrm{g})$ and the lowest adsorption occurred at $\mathrm{pH} 2(4.1 \mathrm{mg} / \mathrm{g})$. The apparent equilibrium was reached after 120 min. Optimal experimental conditions were determined. In order to determine the bestfit-adsorption Kinetics, the experimental data were analyzed using pseudo-first-order, pseudo-second-order, pseudo-third-order, Esquivel, and Elovich models. Linear regressive and non-linear regressive methods were used to obtain the relative parameters. The statistical functions were estimated to find the suitable method which fit better the experimental data. Both methods were suitable to obtain the parameters. The non-linear pseudo-first-order model was the best to fit the equilibrium data. The present work showed that activated carbon can be used as a low cost adsorbent for the malachite green removal from water.
\end{abstract}

Keywords: Activated carbon (AC), malachite green (MG), linear, non-linear regression.

\section{Introduction}

Malachite green (MG) is used in coloring paper, dyeing cottons, wools, silk, leather and coating for paper stock. The treatment of effluents containing such dyes is of great interest due to their harmful impacts on receiving waters [1]. The best efficient method used for the quickly removal of dyes from the aqueous solution is the physical adsorption [2]. Aromatic solutes showed slighty better adsorption than aliphatic solutes, due to the potential to form $\pi-\pi$ bonds with the basal planes of activated carbon. No significant influence of solute charge or size was observed [3]. This work aims to understand the potential of activated

\footnotetext{
* Corresponding author. E-mail address: benmaamarzoubir@yahoo.fr
} 
carbon (AC) to remove MG dye from simulated aqueous solution in batch mode. The adsorption kinetics efficiency of MG was investigated in order to optimize the experimental parameters such as contact time and $\mathrm{pH}$ at an agitation speed of $300 \mathrm{rpm}$, initial adsorbent concentration of $5 \mathrm{mg} / \mathrm{L}$ and temperature of $25^{\circ} \mathrm{C}$. The statistical functions were used to estimate the error deviations between experimental and theoretically predicted adsorption kinetic values, including Linear and non-linear method. The optimization procedure required a defined error function in order to evaluate the fit of equation to the experimental data.

\section{Material and methods}

MG (4-(4-(dimethylamino) alpha-phenylbenzylidene)-2,5-cyclohexadien-1ylidene) dimethylammonium chloride, $\mathrm{C}_{23} \mathrm{H}_{25} \mathrm{ClN}_{2}, \mathrm{Mw}=364 \mathrm{~g} / \mathrm{mol}$ (Fig. 1) used in the present study, was purchased from Merck (Germany) and was selected from the list of dyes normally used in Algeria. The sieved residue of fruit of Sapindus was washed with distilled water to remove any residues or impurities. Subsequently, it was dried in an oven for 12 hours at $80{ }^{\circ} \mathrm{C}$. The material was pyrolysized in a fluidized bed furnace at different temperature range. The pyrolysis process was undergone at temperatures of 300, 400 and $500{ }^{\circ} \mathrm{C}$ for half an hour. Then, the material produced was discharged from the first cyclone of the fluidized bed furnace. This fast pyrolysis method produced variety of material at different temperatures. Activation of the material was done by using steam average flowrate $300 \mathrm{cc} / \mathrm{min}$ at $800{ }^{\circ} \mathrm{C}$ in a muffle furnace for 1 and 2 hours. The activated carbon was then ground and dried in an oven at $100{ }^{\circ} \mathrm{C}$ for overnight.

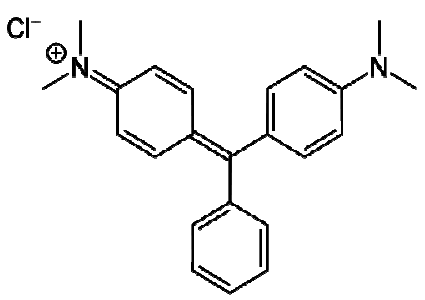

Figure 1. Structure of malachite green [4].

Adsorption kinetics of MG onto AC was studied in a batch system. The effects of $\mathrm{pH}$ and equilibrium time were examined. The adsorption parameters were optimized. In each experiment pre weighed amount of adsorbent $(50 \mathrm{mg}$ ) was added to $50 \mathrm{~mL}$ of dye solution $(5 \mathrm{mg} / \mathrm{L})$ taken in a $250 \mathrm{~mL}$ of conical flask and $0.1 \mathrm{M} \mathrm{NaOH}$ or $0.1 \mathrm{M} \mathrm{HCl}$ were added to adjust the $\mathrm{pH}$ value. This solution was agitated at $300 \mathrm{rpm}$ and centrifugated. The $\mathrm{MG}$ concentration in solution was determined at $\lambda \max =620 \mathrm{~nm}$ by spectrophotometer UV-1700 PHARMA SPEC SHIMADZU. The amount of MG adsorbed per mass unit of adsorbent at time $t$, $\mathrm{q}(\mathrm{mg} / \mathrm{g})$, (Eq. (1)) was calculated as:

$$
q=\left(C_{0}-C\right) \frac{V}{M}
$$


where $\mathrm{C}_{0}$ is the initial MG concentration $(\mathrm{mg} / \mathrm{L}), \mathrm{C}$ is the dye concentration at time $\mathrm{t}, \mathrm{V}$ is the solution volume (L) and $\mathrm{M}$ is the adsorbent mass [g) [5]. The effect of $\mathrm{pH}$ was conducted by mixing $1 \mathrm{~g}$ of adsorbent with $1 \mathrm{~L}$ of MG synthetic solution of $5 \mathrm{mg} / \mathrm{L}$. The solution $\mathrm{pH}$ was varied from 2 to 12 , by adding $0.1 \mathrm{M}$ $\mathrm{NaOH}$ or $0.1 \mathrm{M} \mathrm{HCl}$ solutions. The suspension was shaken for $24 \mathrm{~h}$ at $25{ }^{\circ} \mathrm{C}$. Kinetic experiments were performed by mixing $50 \mathrm{~mL}$ of dye solution $(5 \mathrm{mg} / \mathrm{L})$ with $50 \mathrm{mg}(0.05 \mathrm{~g})$ of adsorbent. The initial $\mathrm{pH}$ for each dye solution was set at 6. The suspensions were kept under agitation during 24 hours. MG concentrations in the supernatants were calculated and allowed to determine the amount adsorbed of dyes onto AC. The experiments were realized against time $(5,10,15,20,25,30,40,50,60,90,120,150,180,240$ and $300 \mathrm{~min})$.

\section{Results and discussion}

To study the effect of every parameter, it is necessary to fix the values of others. The elimination of pollutant from simulated aqueous solution by adsorption is extremely influenced by the medium of the solution which affects the nature of the adsorbent surface charge, the ionization extent, the aqueous adsorbate species speciation and the adsorption rate. The adsorptive process through functional groups dissociation on the adsorbate and adsorbent were affected by a $\mathrm{pH}$ change [6]. The adsorption of MG increases with the increase of $\mathrm{pH}$ of the solution. Fig. 2 shows the effect of the $\mathrm{pH}$ on the adsorption capacity of $\mathrm{MG}$ onto AC at various initial solution $\mathrm{pH}$ in the range $2-12$ under the following conditions: initial dye concentration of $5 \mathrm{mg} / \mathrm{L}$ and AC dose of $1 \mathrm{~g}$. From Fig. 2, we noticed that the $\mathrm{pH}$ of the medium affect strongly the kinetic of MG fixation, showing an increase of the adsorption capacity with the $\mathrm{pH}$, from 4.1 to $4.5 \mathrm{mg} / \mathrm{g}$ for $\mathrm{pH}$ increasing from 2 to 6 .

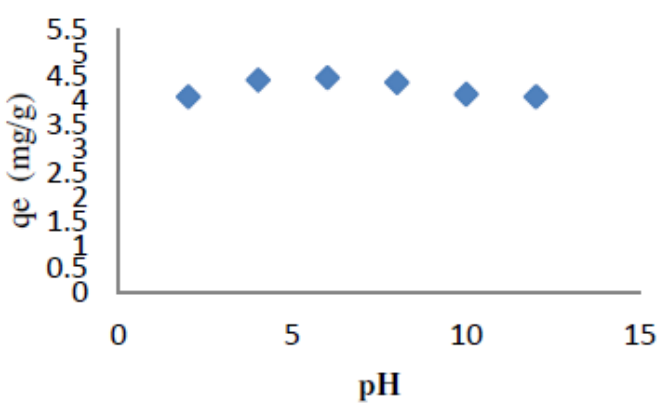

Figure 2. Effect of the initial $\mathrm{pH}$ on the AC equilibrium adsorption capacity.

From this study, it is obvious that in the basic medium, the negatively charged species tends dominating and the surface began to acquire a negative charge. In this case the adsorbent surface is negatively charged. The MG adsorption increased due to the increasing of electrostatic attractions between the negative charge of AC particles and the positive charge of MG species.

Fig. 3 highlights the adsorption Kinetics of MG onto AC. In the light of the result, the synthetic sample could be divided in three zones: (i) 0-30 min, which indicated the fast adsorption of $\mathrm{MG}$, suggesting rapid external diffusion and 
surface adsorption; (ii) 30-60 min, showed a gradual equilibrium, and (iii) 60-300 min, indicated the plateau of the equilibrium state. The adsorption was rapid at the initial stage of the contact, but it gradually slowed down until the equilibrium.

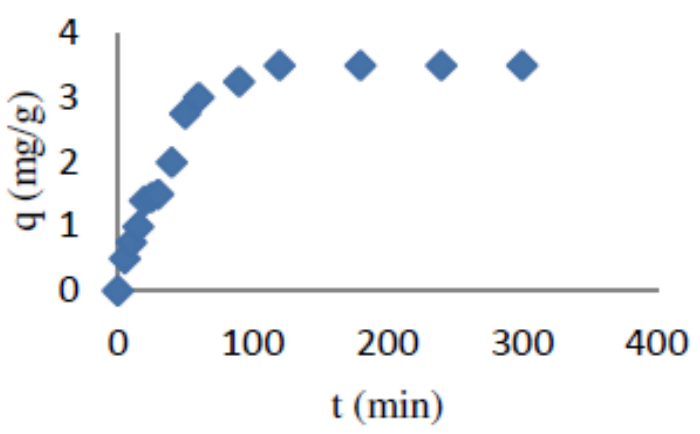

Figure 3. MG adsorption kinetic on AC.

The fast adsorption at the initial stage can be attributed to the fact that a large number of surface sites are available for adsorption. After a lapse of time, the remaining surface sites are difficult to be occupied because of the repulsion between the solute molecules of the solid and bulk phases make it take too long time to reach equilibrium. Adsorption is a complex process whereby it is influenced by several parameters related to adsorbent and to the physicochemical conditions under which the process is carried out [7]. In order to understand the mechanism of the adsorption process, the following equations: [pseudo-first order (Lagergren Model) [1], pseudo-second order [8], Esquivel [9], pseudo-third order [10], and Elovich [11]] were selected to fit the experimental kinetic data. Equations of these models were illustrated in Table 1.

Table 1. Adsorption kinetics models and their linear and non-linear forms.

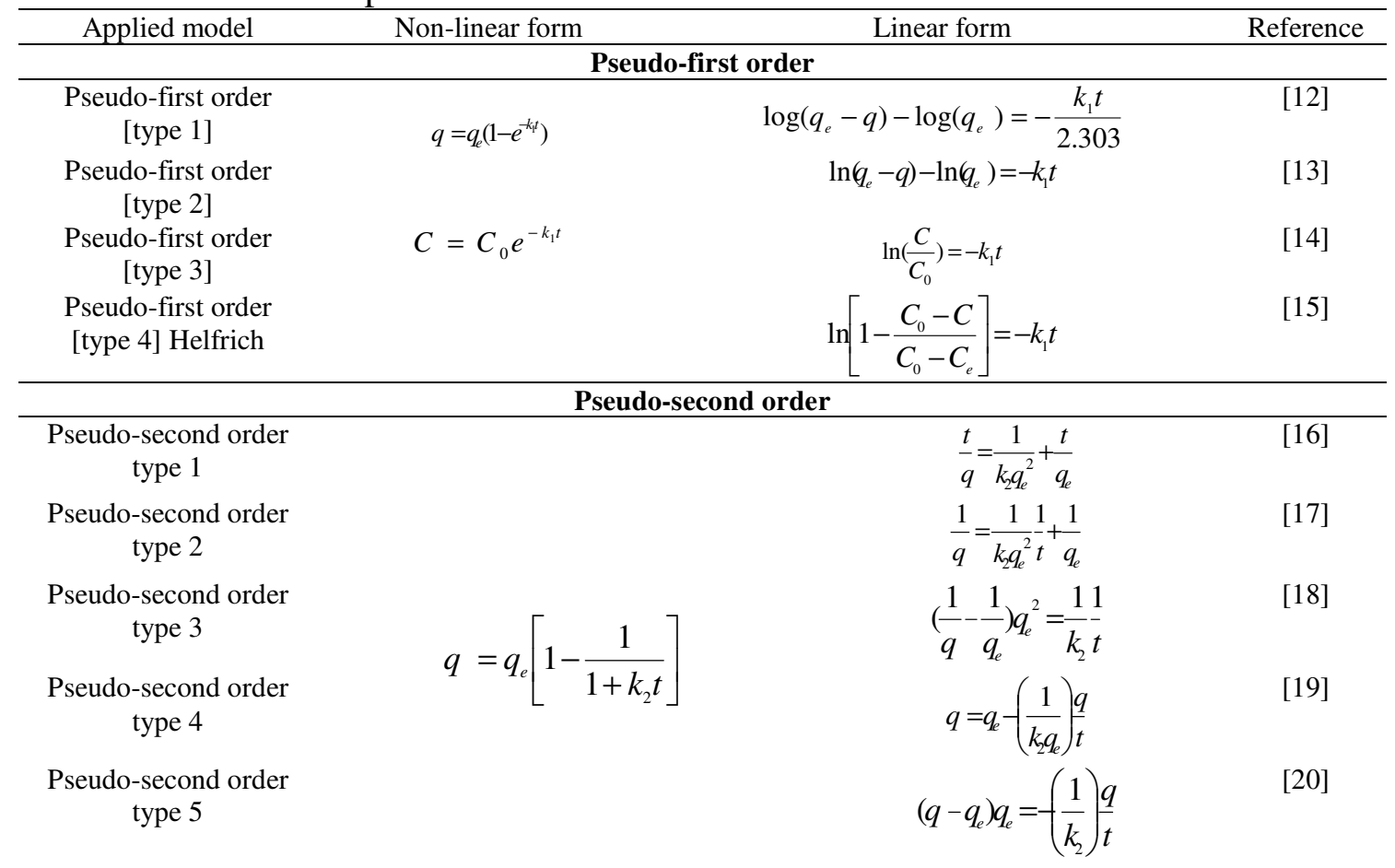




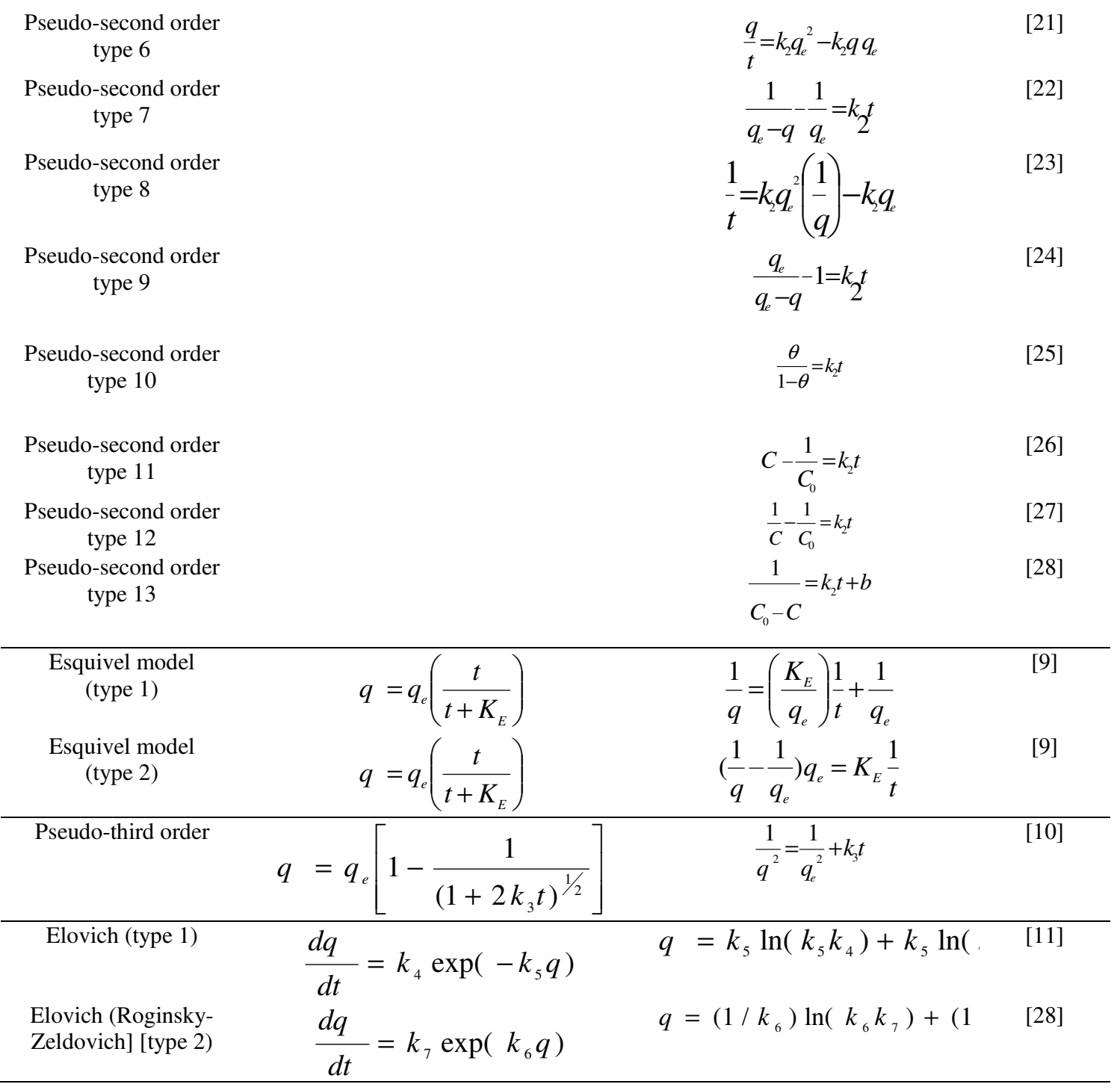

where $\mathrm{k}_{1}$ is pseudo-first order rate constant $\left(\mathrm{min}^{-1}\right), \mathrm{k}_{2}$ is pseudo-second order rate constant $(\mathrm{g} /(\mathrm{mg} \mathrm{min})), \mathrm{k}_{3}$ is pseudo-third order rate constant $\left(\mathrm{g}^{2} /\left(\mathrm{mg}^{2} \mathrm{~min}\right)\right)$, $\mathrm{K}_{\mathrm{E}}$ is Esquivel rate constant ( $\left.\mathrm{min}\right), \mathrm{k}_{4}$ is Elovich rate constant $(\mathrm{mg} /(\mathrm{g} \mathrm{min})), \mathrm{k}_{5}$ is extent of surface coverage and activation energy of the process $(\mathrm{g} / \mathrm{mg}), \mathrm{k}_{6}$ extent of surface coverage and activation energy of the process $(\mathrm{g} / \mathrm{mg}), \mathrm{k}_{7}$ Elovich rate constant $(\mathrm{mg} /(\mathrm{g} \mathrm{min})), \mathrm{q}_{\mathrm{e}}$ is amount of adsorption at equilibrium $(\mathrm{mg} / \mathrm{g})$, and $\theta$ dimensionless parameter $\left(=\mathrm{q} / \mathrm{q}_{\mathrm{e}}\right)$. A non-linear and linear fitting procedure using Excel and Origin software were used, respectively. The constants of all models are given in Table 2.

The optimization procedure required a defined error function in order to evaluate the fit of equation to the experimental data. In this part, the best-fitting equation is determined using the well-known special functions to calculate the error deviation between experimental and predicted data. The mathematical equations of these error functions are illustrated in Table 3. 
Table 2. A Linear and non-linear Pseudo-first order, Pseudo-second order, Esquivel, Pseudo-third order and Elovich kinetics constants related to the adsorption of MG onto AC.

\begin{tabular}{|c|c|c|}
\hline Model & Linear Method & Non-linear Method \\
\hline & Pseudo-first order (type 1) & Non-linear Pseudo-first order (type 1) \\
\hline $\mathrm{q}_{\mathrm{e}}$ & 3.501 & \multirow{9}{*}{$\begin{array}{c}3.600 \\
0.023 \\
0.983 \\
\mathrm{q}=3.600 *(1-\exp (-0.023 * \mathrm{t}))\end{array}$} \\
\hline $\mathrm{K}_{1}$ & 0.001 & \\
\hline $\mathrm{R}^{2}$ & 0.843 & \\
\hline Equation & $\log (q e-q)-\log (q e)=-0.015 * t$ & \\
\hline \multicolumn{2}{|r|}{ Pseudo-first order (type 2) } & \\
\hline $\mathrm{q}_{\mathrm{e}}$ & 3.501 & \\
\hline $\mathrm{K}_{1}$ & 0.034 & \\
\hline $\mathrm{R}^{2}$ & 0.843 & \\
\hline Equation & $\ln (\mathrm{qe}-\mathrm{q})-\ln (\mathrm{qe})=-0.034 * \mathrm{t}$ & \\
\hline & $\begin{array}{r}\text { Pseudo-first order (type } \\
\text { order (type }\end{array}$ & Non-linear Pseudo-first \\
\hline $\mathrm{C}_{0}$ & 5 & \multirow{9}{*}{$\begin{array}{c}5 \\
0.011 \\
0.773 \\
\mathrm{C}=5^{*} \exp (-0.011 * t)\end{array}$} \\
\hline $\mathrm{K}_{1}$ & 0.005 & \\
\hline $\mathrm{R}^{2}$ & 0.419 & \\
\hline Equation & $\ln (\mathrm{C} / \mathrm{C} 0)=-0,005 * \mathrm{t}$ & \\
\hline & Pseudo-first order (type 4) & \\
\hline $\mathrm{C}_{0}$ & 5 & \\
\hline $\mathrm{K}_{1}$ & 0.006 & \\
\hline $\mathrm{R}^{2}$ & 0.457 & \\
\hline Equation & $\operatorname{Ln}\left(1-\left(\left(\mathrm{C}_{0}-\mathrm{C}\right) /\left(\mathrm{C}_{0}-\mathrm{C}_{\mathrm{e}}\right)=-0.006 * \mathrm{t}\right.\right.$ & \\
\hline \multicolumn{3}{|c|}{ Pseudo-second order (type 1) } \\
\hline $\mathrm{q}_{\mathrm{e}}$ & 4.081 & \multirow{31}{*}{$\begin{array}{c}4.297 \\
0.025 \\
0.963 \\
\mathrm{q}=4.297 *(1-(1 /(1+0.025 * \mathrm{t})))\end{array}$} \\
\hline $\mathrm{K}_{2}$ & 0.007 & \\
\hline $\mathrm{R}^{2}$ & 0.986 & \\
\hline Equation & $(\mathrm{t} / \mathrm{q})=0.245 * \mathrm{t}+8.959$ & \\
\hline & ido-second order (type 2) & \\
\hline $\mathrm{q}_{\mathrm{e}}$ & 3.876 & \\
\hline $\mathrm{K}_{2}$ & 335.449 & \\
\hline $\mathrm{R}^{2}$ & 0.974 & \\
\hline Equation & $1 / \mathrm{q}=9.303 *(1 / \mathrm{t})+0.258$ & \\
\hline \multicolumn{2}{|c|}{ Pseudo-second order (type 3) } & \\
\hline $\mathrm{q}_{\mathrm{e}}$ & 3.610 & \\
\hline $\mathrm{K}_{2}$ & 0.008 & \\
\hline $\mathrm{R}^{2}$ & 0.974 & \\
\hline Equation & $\left((1 / \mathrm{q})-\left(1 / \mathrm{q}_{\mathrm{e}}\right)\right) *\left(\mathrm{q}_{\mathrm{e}}^{2}\right)=118.9 *(1 / \mathrm{t})$ & \\
\hline \multicolumn{2}{|c|}{ Pseudo-second order (type 4) } & \\
\hline $\mathrm{q}_{\mathrm{e}}$ & 4.279 & \\
\hline $\mathrm{K}_{2}$ & 0.006 & \\
\hline $\mathrm{R}^{2}$ & 0.821 & \\
\hline Equation & $\mathrm{q}=-41.28 *(\mathrm{q} / \mathrm{t})+4.272$ & \\
\hline \multicolumn{2}{|c|}{ Pseudo-second order (type 5) } & \\
\hline $\mathrm{q}_{\mathrm{e}}$ & 4.210 & \\
\hline $\mathrm{K}_{2}$ & 0.001 & \\
\hline $\mathrm{R}^{2}$ & 0.821 & \\
\hline Equation & $(\mathrm{q}-\mathrm{qe}) * \mathrm{qe}=-169.000 *(\mathrm{q} / \mathrm{t})$ & \\
\hline \multicolumn{2}{|c|}{ Pseudo-second order (type 6) } & \\
\hline $\mathrm{q}_{\mathrm{e}}$ & 4.895 & \\
\hline $\mathrm{K}_{2}$ & 0.004 & \\
\hline $\mathrm{R}^{2}$ & 0.821 & \\
\hline Equation & $(q / t)=-0.019 * q+0.093$ & \\
\hline \multicolumn{2}{|c|}{ Pseudo-second order (type 7) } & \\
\hline $\begin{array}{c}\mathrm{q}_{\mathrm{e}} \\
\mathrm{K}_{2}\end{array}$ & $\begin{array}{c}3.69 \\
0.021\end{array}$ & \\
\hline
\end{tabular}




\begin{tabular}{|c|c|c|}
\hline $\begin{array}{c}\mathrm{R}^{2} \\
\text { Equation }\end{array}$ & $\begin{array}{c}0.843 \\
(1 /(\mathrm{qe}-\mathrm{q}))-(1 / \mathrm{qe})=0.021 * \mathrm{t}\end{array}$ & \\
\hline \multicolumn{2}{|c|}{ Pseudo-second order (type 8) } & \\
\hline $\mathrm{q}_{\mathrm{e}}$ & 4.000 & \\
\hline $\mathrm{K}_{2}$ & 0.006 & \\
\hline $\mathrm{R}^{2}$ & 0.974 & \\
\hline Equation & $1 / \mathrm{t}=0.104 *(1 / \mathrm{q})-0.026$ & \\
\hline \multicolumn{2}{|c|}{ Pseudo-second order (type 9) } & \\
\hline $\mathrm{q}_{\mathrm{e}}$ & 3.690 & \\
\hline $\mathrm{K}_{2}$ & 0.078 & \\
\hline $\mathrm{R}^{2}$ & 0.843 & \\
\hline Equation & $(\mathrm{qe} /(\mathrm{qe}-\mathrm{q}))-1=0.078 * \mathrm{t}$ & \\
\hline \multicolumn{2}{|c|}{ Pseudo-second order (type 10) } & \\
\hline $\mathrm{q}_{\mathrm{e}}$ & 3.690 & \\
\hline $\mathrm{K}_{2}$ & 0.078 & \\
\hline $\mathrm{R}^{2}$ & 0.843 & \\
\hline Equation & $(\theta /(1-\theta))=0.078 * \mathrm{t}$ & \\
\hline \multicolumn{3}{|c|}{ Pseudo-second order (type 11) } \\
\hline $\mathrm{C}_{0}$ & 5.000 & \\
\hline $\mathrm{K}_{2}$ & 0.009 & \\
\hline $\mathrm{R}^{2}$ & -4.210 & \\
\hline Equation & $\left(\mathrm{C}-\left(1 / \mathrm{C}_{0}\right)\right)=0.009 * \mathrm{t}$ & \\
\hline \multicolumn{2}{|c|}{ Pseudo-second order (type 12) } & \\
\hline $\mathrm{C}_{0}$ & 5.000 & \\
\hline $\mathrm{K}_{2}$ & 0.002 & \\
\hline $\mathrm{R}^{2}$ & 0.655 & \\
\hline Equation & $\left((1 / \mathrm{C})-\left(1 / \mathrm{C}_{0}\right)\right)=0.002 *_{\mathrm{t}}$ & \\
\hline \multicolumn{2}{|c|}{ Pseudo-second order (type 13) } & \\
\hline $\mathrm{C}_{0}$ & 5.000 & \\
\hline $\mathrm{K}_{2}$ & 0.003 & \\
\hline $\mathrm{R}^{2}$ & 0.334 & \\
\hline Equation & $\left(1 /\left(\mathrm{C}_{0}-\mathrm{C}\right)\right)=-0.003 * \mathrm{t}+0.910$ & \\
\hline \multicolumn{3}{|c|}{ Esquivel Model (type 1) } \\
\hline $\mathrm{q}_{\mathrm{e}}$ & 3.876 & \multirow{9}{*}{$\begin{array}{c}4.296 \\
39.642 \\
0.963 \\
\mathrm{q}=2.145^{*}(\mathrm{t} /(\mathrm{t}+7.322))\end{array}$} \\
\hline $\mathrm{K}_{\mathrm{E}}$ & 36.058 & \\
\hline $\mathrm{R}^{2}$ & 0.974 & \\
\hline Equation & $1 / \mathrm{q}=9.303 *(1 / \mathrm{t})+0.258$ & \\
\hline & quivel Model (type 2) & \\
\hline $\mathrm{q}_{\mathrm{e}}$ & 3.610 & \\
\hline $\mathrm{K}_{\mathrm{E}}$ & 32.940 & \\
\hline $\mathrm{R}^{2}$ & 0.974 & \\
\hline Equation & $(((1 / \mathrm{q})-(1 / \mathrm{q})) * \mathrm{qe})=32.940 *(1 / \mathrm{t})$ & \\
\hline \multicolumn{3}{|c|}{ Pseudo-third order (type 1) } \\
\hline $\mathrm{q}_{\mathrm{e}}$ & 0.957 & \\
\hline $\mathrm{K}_{3}$ & -0.005 & \\
\hline $\mathrm{R}^{2}$ & 0.202 & \\
\hline Equation & $\left(1 / \mathrm{q}^{2}\right)=-0.005 * \mathrm{t}+1.092$ & \\
\hline \multicolumn{3}{|c|}{ Elovich (type 1) } \\
\hline $\mathrm{K}_{4}$ & 0.300 & \\
\hline $\mathrm{K}_{5}$ & 0.897 & \\
\hline $\mathrm{R}^{2}$ & 0.937 & \\
\hline Equation & $\mathrm{q}=0.897 * \ln (\mathrm{t})-1.178$ & \\
\hline \multicolumn{3}{|c|}{ Elovich (type 2) } \\
\hline $\mathrm{K}_{4}$ & 0.241 & \\
\hline $\mathrm{K}_{5}$ & 1.114 & \\
\hline $\mathrm{R}^{2}$ & 0.937 & \\
\hline Equation & $\mathrm{q}=0.897 * \ln (\mathrm{t})-1.178$ & \\
\hline
\end{tabular}


Table 3. Mathematical equations of error functions.

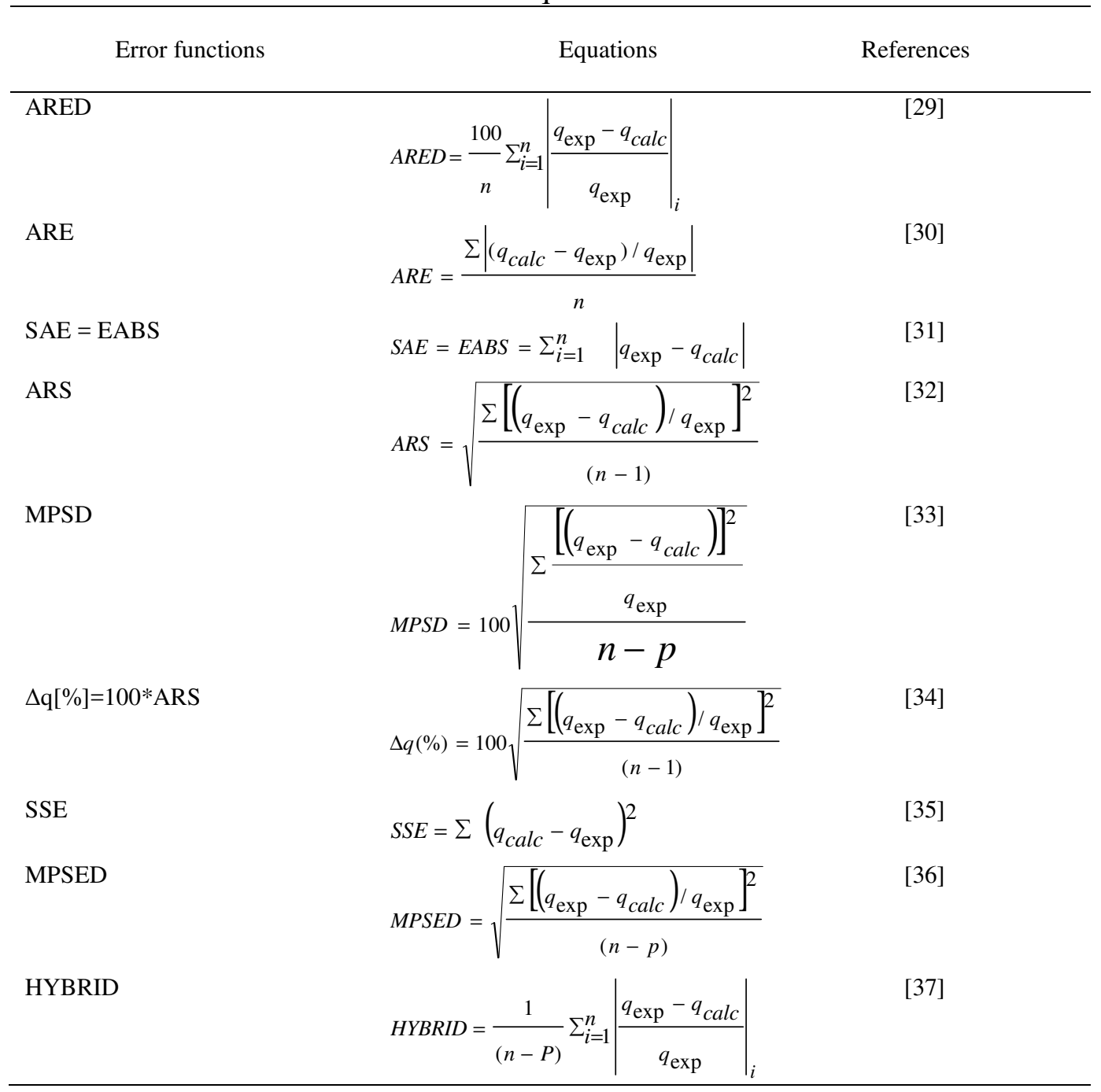

where $n$ is the number of experimental data points, $q_{\text {calc }}$ is the predicted (calculated) quantity of $\mathrm{MG}$ adsorbed onto $\mathrm{AC}, q_{\exp }$ are the experimental data, $\mathrm{p}$ is the number of parameters in each kinetic model, ARED is the average relative error deviation (dimensionless parameter), ARE is the average relative error (dimensionless parameter, ARS is the average relative standard error (dimensionless parameter), HYBRID is the hybrid fractional error function (dimensionless parameter), MPSD Marquardt's is the percent standard deviation (dimensionless parameter), MPSED Marquardt's is the percent standard deviation (dimensionless parameter), $\mathrm{SAE}=\mathrm{EABS}$ is the sum of absolute error $(\mathrm{mg} / \mathrm{g}), \mathrm{SSE}$ is the sum of the squares of the errors $(\mathrm{mg} / \mathrm{g})^{2}$, and $\Delta \mathrm{q}(\%)$ is the normalized standard deviation $(\mathrm{mg} / \mathrm{g})$. The constants of all error analysis are represented in Table 4. 
Table 4. Error deviation data related to the MG adsorption onto AC using most commonly used functions.

\begin{tabular}{|c|c|c|c|c|c|c|c|c|c|}
\hline Error functions & ARED & $\mathrm{SAE}=\mathrm{EABS}$ & MPSED & SSE & HYBRID & ARE & ARS & $\Delta q(\%)=100 * A R S$ & MPSD \\
\hline \multirow{3}{*}{$\begin{array}{c}\text { Linear } \\
\text { eudo-first order type 1 } \\
\text { near pseudo-first order } \\
\text { type } 2 \\
\text { on Linear pseudo-first } \\
\text { order type 1- }\end{array}$} & 88.296 & 27.01 & 0.957 & 62.345 & 1.03 & 0.883 & 0.92 & 91.985 & 139.372 \\
\hline & 16.785 & 3.238 & 0.262 & 1.577 & 0.196 & 0.168 & 0.252 & 25.18 & 30.21 \\
\hline & 7.418 & 1.878 & 0.104 & 0.372 & 0.086 & 0.074 & 0.1 & 10.035 & 12.491 \\
\hline \multirow{2}{*}{$\begin{array}{l}\text { inear pseudo-second } \\
\text { order type 1 } \\
\text { inear pseudo-second } \\
\text { order type 2 }\end{array}$} & 53.541 & 15.202 & 0.599 & 19.59 & 0.624 & 0.535 & 0.575 & 57.557 & 81.729 \\
\hline & 150.535 & 22.657 & 2.595 & 53.576 & 1.756 & 1.505 & 2.493 & 249.307 & 221.741 \\
\hline \multirow{2}{*}{$\begin{array}{l}\text { inear pseudo-second } \\
\text { order type } 3 \\
\text { inear pseudo-second } \\
\text { order type } 4\end{array}$} & 52.495 & 15.165 & 0.582 & 19.46 & 0.612 & 0.525 & 0.559 & 55.964 & 77.503 \\
\hline & 56.451 & 16.019 & 0.631 & 21.709 & 0.658 & 0.564 & 0.607 & 60.67 & 86.129 \\
\hline $\begin{array}{l}\text { inear pseudo-second } \\
\text { order type } 5\end{array}$ & 85.274 & 25.928 & 0.926 & 57.19 & 0.995 & 0.853 & 0.889 & 88.957 & 134.008 \\
\hline $\begin{array}{l}\text { inear pseudo-second } \\
\text { order type } 6\end{array}$ & 61.762 & 17.55 & 0.69 & 26.031 & 0.72 & 0.617 & 0.663 & 66.314 & 94.32 \\
\hline \multirow{2}{*}{$\begin{array}{l}\text { inear pseudo- second } \\
\text { order type } 7 \\
\text { inear pseudo- second } \\
\text { order type } 8\end{array}$} & 18.704 & 6.069 & 0.221 & 3.961 & 0.218 & 0.187 & 0.213 & 21.277 & 33.97 \\
\hline & 55.365 & 15.806 & 0.617 & 21.105 & 0.646 & 0.553 & 0.593 & 59.318 & 84.577 \\
\hline $\begin{array}{l}\text { inear pseudo- second } \\
\text { order type } 9\end{array}$ & 41.342 & 6.62 & 0.644 & 5.594 & 0.482 & 0.413 & 0.619 & 61.912 & 63.684 \\
\hline \multirow{2}{*}{$\begin{array}{l}\text { inear pseudo- second } \\
\text { order type } 10 \\
\text { n-linear pseudo- second } \\
\text { order type } 1\end{array}$} & 41.342 & 6.62 & 0.644 & 5.594 & 0.482 & 0.413 & 0.619 & 61.912 & 63.684 \\
\hline & 10.03 & 2.856 & 0.126 & 0.804 & 0.117 & 0.1 & 0.121 & 12.109 & 17.097 \\
\hline \multirow{2}{*}{$\begin{array}{l}\text { inear Esquivel type } 1 \\
\text { inear Esquivel type } 2\end{array}$} & 150.043 & 22.601 & 2.584 & 53.275 & 1.75 & 1.5 & 2.482 & 248.245 & 220.95 \\
\hline & 132.837 & 18.876 & 2.359 & 42.237 & 1.55 & 1.328 & 2.267 & 226.707 & 200.085 \\
\hline Non-linear Esquivel & 10.199 & 2.881 & 0.128 & 0.803 & 0.119 & 0.102 & 0.123 & 12.355 & 17.256 \\
\hline \multirow{2}{*}{$\begin{array}{c}\text { Linear Elovich } \\
\text { model type } 1 \\
\text { Linear Elovich } \\
\text { model type 2 }\end{array}$} & 15.884 & 3.891 & 0.208 & 1.353 & 0.185 & 0.159 & 0.2 & 19.979 & 23.516 \\
\hline & 15.884 & 3.891 & 0.208 & 1.353 & 0.185 & 0.159 & 0.2 & 19.979 & 23.516 \\
\hline
\end{tabular}

Adsorption kinetic data are the basic requirements for the design of adsorption systems. In order to optimize the design of a specific sorbate/sorbent system to remove MG from aqueous solution, it is important to establish the most appropriate correlation for the experimental kinetic data. Applicability of some statistical tools to predict optimum adsorption kinetic of MG onto AC after linear regression analysis showed that the highest $\mathrm{R}^{2}$ value and the lowest ARED, ARE, SAE, ARS, MPSD, $\triangle \mathrm{q}$, SSE, MSPED, and HYBRID values could be suitable and meaningful tools to predict the best-fitting equation models. The best fitting is determined based on the use of these functions to calculate the error deviation between experimental and predicted equilibrium adsorption kinetic data, after linear analysis. Hence, according to Table 4, it seems that the non-linear pseudofirst order model was the most suitable model to satisfactorily describe the studied adsorption phenomenon. Therefore, based on these mentioned results, the best useful error estimation statistical tools should point out the non-linear pseudo-first order model followed by non-linear pseudo-second order and nonlinear Esquivel as the best-fitting models.

\section{Conclusion}

AC was used for the MG adsorption in simulated aqueous solution. In batch mode, the adsorption was highly dependent on various operating parameters, such as contact time, and $\mathrm{pH}$. The obtained results allowed to establish the following optimal conditions: 120 min time contact and $\mathrm{pH} 6$ leading to $70 \%$ MG removal obtained at home temperature. The adsorption kinetic of MG onto AC can be better fitted by the pseudo-second order linear model [type 9 and type 10) as compared to the non-linear pseudo-second-order model, linear pseudosecond-order model, pseudo first order, pseudo third order, and Esquivel models. 
On the whole, the experimental results showed that $\mathrm{AC}$ is suitable adsorbent for the removal of MG dye.

\section{References}

1. Kushwaha AK, Gupta N, Chattopadhyaya MC. Removal of cationic methylene blue and malachite green dyes from aqueous solution by waste materials of Daucus carota. J Saudi Chem Soc. 2014;18:200-207.

2. Allen SJ, Koumanova B. Decolourisation of water/wastewater using adsorption. J Univ Chem Technol Metal. 2005;40:175-192.

3. De Ridder DJ. Adsorption of organic micropollutants onto activated carbon and zeolites. Netherlands: Water Management Acad Press; 2012.

4. Al-Degs YS, Sweileh JA. Simultaneous determination of five commercial cationic dyes in stream waters using diatomite solid-phase extractant and multivariate calibration. Arab J Chem. 2012;5:219-224.

5. Santhi T, Manonmani S, Smitha T, et al. Adsorption kinetics of cationic dyes from aqueous solution by bioadsorption onto activated carbon prepared from Cucumis Sativa. J Appl Sci Environ Sanit. 2009;4:263-271.

6. Khattria SD, Singh MK. Removal of malachite green from dye wastewater using neem sawdust by adsorption. J Hazard Mater. 2009;167:1089-1094.

7. Dahri MK, Kooh MRR, Lim LBL. Water remediation using low cost adsorbent walnut shell for removal of malachite green: Equilibrium; kinetics; thermodynamic and regeneration studies. J Environ Chem Eng. 2014;2:1434-1444.

8. Baek MH, Ijagbemi CO, Kim DS. Removal of Malachite Green from aqueous solution using degreased coffee bean. $\mathrm{J}$ Hazard Mater. 2010;176:820-828.

9. Shilpi A, Shivhare US, Basu S. Supercritical $\mathrm{CO}_{2}$ Extraction of Compounds with Antioxidant Activity from Fruits and Vegetables Waste. Foc Modern Food Ind. 2013;2:43-62.

10. Kyzas GZ, Lazaridis NK, Mitropoulos AC. Removal of dyes from aqueous solutions with untreated coffee residues as potential low-cost adsorbents: Equilibrium; reuse and thermodynamic approach. Chem Eng J. 2012;189190:148-159.

11. Secula MC, Cagnon B, Creţescu I, et al. Studii şi Cercetări Ştiinţifice Chimie şi Inginerie Chimică. Biotehnologii Industrie Alimentară. 2011;12:307.

12. Santhi T, Manonmani S, Smitha T. Kinetics and Isotherm Studies on Cationic Dyes Adsorption onto Annona Squmosa Seed Activated Carbon. Int J Eng Sci Technol. 2010;2:287-295.

13. Tavlieva MP, Genieva SD, Georgieva VG, et al. Kinetic study of brilliant green adsorption from aqueous solution onto white rice husk ash. J Colloid Interf Sci. 2013;409:112-122.

14. Keng CS, Zainal Z, Abdullah AH. Removal of cationic and anionic dyes by immobilized titanium dioxide loaded activated carbon. Malays J Anal Sci. 2008;12:451-457. 
15 Rao VS, Chakrapani C, Babu CS, et al. Studies on sorption of fluoride by prepared activated Kaza's carbons. Der Pharma Chem. 2011;3:73-83.

16. Wu FC, Tseng RL, Juang RS. Kinetic modeling of liquid-phase adsorption of reactive dyes and metal ions on chitosan. Water Res. 2001;35:613-618.

17. Shen K, Gondal MA. Removal of hazardous Rhodamine dye from water by adsorption onto exhausted coffee ground. J Saudi Chem Soc. 2017;21:S120-S127.

18. Sheng GD, Li JX, Shao DD, et al. Adsorption of copper(II) on multiwalled carbon nanotubes in the absence and presence of humic or fulvic acids. $\mathbf{J}$ Hazard Mater.2010;178:333-340.

19. Schierz A, Zaenker H. Aqueous suspensions of carbon nanotubes: surface oxidation; colloidal stability and uranium sorption. Environ Pollut. 2009;157:1088-1094.

20. Ho YS. Second-order kinetic model for the sorption of cadmium onto tree fern: A comparison of linear and non-linear methods Water Res. 2006;40:119-125.

21. Giannakopoulos E, Christoforidis $\mathrm{KC}$, Tsipis $\mathrm{A}$, et al. Influence of $\mathrm{Pb}(\mathrm{II})$ on the radical properties of humic substances and model compounds. J Phys Chem A. 2005;109:2223-2232.

22. Escudero C, Gabaldon C, Marzal P, et al. Effect of EDTA on divalent metal adsorption onto grape stalk and exhausted coffee wastes. J Hazard Mater. 2008;152:476-485.

23. Kumar KV. Linear and non-linear regression analysis for the sorption kinetics of methylene blue onto activated carbon. J Hazard Mater. 2006;137:1538-1544.

24. Kumar KV, Ivanesan S. Pseudo second order kinetics and pseudo isotherms for malachite green onto activated carbon: Comparison of linear and nonlinear regression methods. J Hazard Mater. 2006;36:721-726.

25 Sobkowsk J, Czerwinski A. Kinetics of carbon dioxide adsorption on a platinum electrode. J Electroanal Chem. 1974;55:391-397.

26. Pereira L, Alves M. Dyes: Environmental impact and remediation. In: Environmental Protection Strategies for Sustainable Development Strategies for Sustainability. Malik A, Grohmann E, eds. Springer; 2012. pp 111-162.

27. Blanachard G, Maunaye M, Martin G. Removal of heavy metals from waters by means of natural zeolites. Water Res. 1984;18:1501-1507.

28. Ho YS, Ng JCY, McKay G. Kinetics of pollutant sorption by biosorbents, Review. Sep Purif Meth. 2000;29:189-232.

29. Riahi K, Chaabane S, Ben-Thayer B. A kinetic modeling study of phosphate adsorption onto Phoenix dactylifera L. date palm fibers in batch mode. J Saudi Chem Soc. 2017;21:S143-S152.

30. Han R, Zhang J, Han P, et al. Study of equilibrium; kinetic and thermodynamic parameters about methylene blue adsorption onto natural zeolite. Chem Eng J. 2009;145:496-504.

31. Hsu TC. Adsorption of an acid dye onto coal fly ash. Fuel. 2008;87:30403045. 
32. Bajic ZJ, Djokc VR, Velickovic ZS, et al. Equilibrium; kinetic and thermodynamic studies on removal of $\mathrm{Cd}(\mathrm{II})$; $\mathrm{Pb}(\mathrm{II})$ AND $\mathrm{As}(\mathrm{V})$ from wastewater using CARP (Cyprinus Carpio) Scales. Digest J Nanomater Biostruct. 2013;8:1581-1590.

33. Alihosseini A, Taghikhani V, Safekordi AA, et al. Equilibrium sorption of crude oil by expanded perlite using different adsorption isotherms at 298.15 K. Int J Environ Sci Techn. 2010;7:591-598.

34. Wang $\mathrm{L}$, Zhang J, Zhao R, et al. Adsorption of $\mathrm{Pb}(\mathrm{II})$ on activated carbon prepared from Polygonum orientale Linn.: Kinetics; isotherms; $\mathrm{pH}$; and ionic strength studies. Biores Technol. 2010;101:5808-5814.

35. Udoji IA, Etim EE. Dynamics of $\mathrm{M}^{\mathrm{x}+}$ Salts of Fatty Acids Adsorption onto Metallic Ores. Int J Environ Sci Devel. 2015;6: 205-210.

36. Ncibi MC. Applicability of some statistical tools to predict optimum adsorption isotherm after linear and non-linear regression analysis. J Hazard Mater. 2008;153:207-212.

37. Gulipall CS, Prasad B, Wasewar KL. Batch study; equilibrium; and kinetics of adsorption of selenium using Rice Husk Ash (RHA), J Eng Sci Technol. 2011;6: 586-605. 